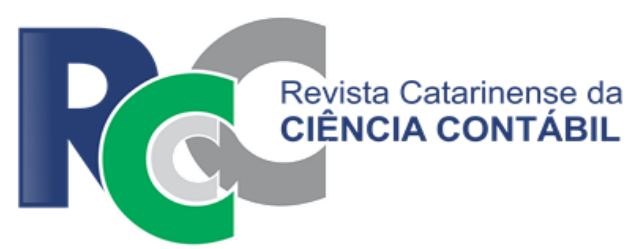

\title{
RELAÇÃO ENTRE A REPUBLICAÇÃO DAS DEMONSTRAÇÕES CONTÁBEIS E O AUDIT DELAY
}

\author{
RELATIONSHIP BETWEEN FINANCIAL RESTATEMENTS AND AUDIT DELAY
}

\begin{abstract}
VANESSA CHIUDINI
Graduada em Ciências Contábeis pela Universidade do Estado de Santa Catarina (UDESC). Acadêmica do curso de especialização em Auditoria e Perícia da UNIDAVI. Endereço: Rua João Aurich, 2300 / Ponto Chic / 89140-000 / Ibirama/SC / Brasil.

E-mail: vanessa.chiudini@hotmail.com
\end{abstract}

PAULO ROBERTO DA CUNHA

Doutor em Ciências Contábeis e Administração pela Universidade Regional de Blumenau (FURB). Professor do Programa de PósGraduação em Ciências Contábeis da FURB (PPGCC/FURB). Professor de Graduação em Ciências Contábeis da UDESC. Endereço: Campus I, Bloco D, Sala 202 / Rua Antônio da Veiga, 140 | Itoupava Seca | 89030-003 / Blumenau/SC / Brasil.

E-mail: pauloccsa@gmail.com

\section{LEANDRO MARQUES}

Mestre em Ciências Contábeis pela Universidade Regional de Blumenau (FURB). Endereço: Campus I, Bloco D, Sala 202 / Rua Antônio da Veiga, 140 / Itoupava Seca | 89030-003 / Blumenau/SC | Brasil.

E-mail: leandromarques@hotmail.com

\section{RESUMO}

O presente trabalho tem por objetivo verificar a relação entre a republicação das demonstrações contábeis e o audit delay. Consiste em uma pesquisa descritiva, do tipo documental, com abordagem quantitativa. A população da pesquisa compreende 495 empresas listadas na BM\&FBovespa. Foram selecionadas para a pesquisa as empresas que apresentaram o Relatório do Auditor Independente sobre as demonstrações contábeis da companhia, entre os anos de 2011 e 2016. Os dados foram analisados por meio de teste de médias e teste de correlação no software SPSS®. Os resultados indicam que há relação entre a republicação das demonstrações contábeis e o audit delay nos anos de 2011, 2012, 2015 e 2016, enquanto que para os anos de 2013 e 2014 tal relação não pôde ser confirmada. Em 2013, não houve diferença significativa no audit delay das empresas que publicaram ou republicaram as demonstrações contábeis. Já, em 2014, observou-se uma relação inversa ao esperado, um menor audit delay relacionado à republicação das demonstrações contábeis. Conclui-se, portanto, que no mercado brasileiro um maior atraso na liberação do relatório do auditor pode sinalizar maiores riscos para a realização da auditoria, dando indícios que as demonstrações podem ser republicadas. Maiores investigações são necessárias para explicar o resultado dissonante observado em 2014.

Palavras-chave: Republicação das demonstrações contábeis. Relatório do auditor independente. Audit Delay. 


\begin{abstract}
The aim of this paper is to verify the relationship between the financial restataments and the audit delay. Consist of a descriptive research, of the document type with quantitative approach. The companies with Audit Report between 2011 and 2016 were selected for the survey. The data were analyzed through means and correlation test in SPSS® software. The results indicate that there is a relationship between the financial restataments and the audit delay in the years 2011, 2012, 2015 and 2016, while for the years 2013 and 2014 this relationship could not be confirmed. In 2013, there was no significant difference in the audit delay of the companies that published or republished the financial statements. Already, in 2014, there was an inverse relation to the expected, a smaller audit delay related to the financial restatements. It is concluded, therefore, that in the Brazilian market a greater delay in the release of the auditor's report may signal greater risks for the audit, giving indications that the statements can be republished. Further research is needed to explain the dissonant outcome observed in 2014.
\end{abstract}

Keywords: Financial restataments. Audit report. Audit delay.

\title{
1 INTRODUÇÃO
}

A evidenciação das informações contábeis está diretamente ligada com a finalidade da Contabilidade, que é promover informações úteis para seus diversos usuários. A evolução da importância da contabilidade aconteceu conforme os usuários tinham necessidade de informações sobre seu patrimônio. Assim, foi-se identificando que tipo de informação cada usuário precisava para a tomada de decisão. Isso, conforme já foi dito, faz entender que o objetivo da contabilidade é fornecer informações relevantes para os distintos tipos de usuários (Dantas, Chaves, Silva, \& Carvalho, 2011; Teixeira, Politelo e Klann, 2013).

Niyama e Silva (2011) elucidam que as informações evidenciadas devem permitir que os usuários analisem o desempenho da entidade em vários períodos, o que faz necessária coerência e padronização no tratamento contábil. Visando a melhorar a comunicação entre investidores, gestores e o mercado universal, a qualidade das informações contábeis fornece maior credibilidade aos investidores.

A definição de evidenciação tende para a divulgação ou a liberação de informações relevantes, quer sob a forma de relatórios financeiros, comunicados de imprensa ou declarações públicas. A qualidade dessas divulgações feitas pelas empresas é de peculiar interesse para os investidores e operadores do mercado de capitais, porque a expectativa é de que quanto maior a qualidade da divulgação, menor a assimetria de informação, o que resulta em menos conflitos entre investidores e gestores (Brown \& Hillegeist, 2008).

Dantas et al. (2011) explicam que o processo de divulgação das informações contábeis, a evidenciação ou disclosure, deve fornecer dados úteis para que haja uma interpretação adequada da situação econômico-financeira da entidade. Para garantir que a evidenciação seja adequada, os órgãos reguladores assumem um papel relevante. Devem especificar o quê e como divulgar e gerir o processo de divulgação. No Brasil, por força das Leis 6.385 de 1976 e 6.404 de 1976, esse papel é desempenhado pela Comissão de Valores Mobiliários (CVM), que disciplinou o processo de apresentação das demonstrações contábeis de uso geral por meio da Deliberação n. -488 de 2005, a fim de garantir a comparação tanto com os relatórios de períodos anteriores quanto com as informações de outras companhias. Essa Deliberação, que aprovou a Norma e Pronunciamento de Contabilidade (NPC) № 27 do Instituto dos Auditores Independentes do Brasil (IBRACON), foi revogada por meio da Deliberação CVM № 595, de 15.9.2009, que referendou o Pronunciamento Técnico № 26 do Comitê de Pronunciamentos Contábeis (CPC), no qual trata da apresentação das demonstrações contábeis.

Essas demonstrações devem fornecer aos mais variados usuários informações sobre a posição patrimonial e financeira, o resultado e o fluxo financeiro das entidades, auxiliando-os em seu processo de tomada de decisão. A CVM, exercendo sua função de fiscalizador, pode identificar problemas no disclosure e determinar o refazimento e a republicação das demonstrações contábeis. Além de observar as normas expedidas pela CVM, as 
demonstrações devem ser obrigatoriamente revisadas por auditores independentes (Dantas et al., 2011).

É nesse contexto que a auditoria assume o importante papel de examinar as demonstrações contábeis e expressar uma opinião sobre a propriedade, bem como assegurar a veracidade das mesmas. Santos, Souza, Machado e Silva (2009) explicam que essa manifestação de opinião, por meio do relatório, é fundamentada em evidências e provas obtidas de procedimentos de auditoria. Esses procedimentos reúnem fatos, formulários, questionamentos, cópias de documentos, observações e anotações que servirão de base para a emissão do parecer do auditor sobre as demonstrações contábeis da empresa.

Com a adoção das Normas Internacionais de Auditoria, o produto final do trabalho, anteriormente chamado de parecer de auditoria, agora é denominado Relatório do Auditor Independente Sobre as Demonstrações Contábeis. O relatório do auditor independente sobre as demonstrações contábeis pode ser classificado em dois grupos: não modificado (anteriormente conhecido como parecer sem ressalva) ou modificado (compreende o parecer com ressalva, parecer adverso e parecer com abstenção de opinião). O relatório do auditor independente sobre as demonstrações contábeis pode ter ressalvas no que se refere à coerência das práticas contábeis, à esfera do processo de exame da auditoria ou à incerteza associada com as grandes contingências não resolvidas (Damascena \& Paulo, 2013).

O período entre o fechamento do exercício social e a data de emissão do relatório do auditor é denominado audit delay. Se o período do audit delay é elevado, é possível que a percepção de risco de informação de desempenho piore para as companhias. Isso pode induzir os investidores a venderem suas ações ou a exigirem remunerações maiores (Pereira \& Costa, 2012).

Pereira e Costa (2012) ressaltam que no quadro brasileiro existe um elemento adicional. Com a adoção das Normas Internacionais de Contabilidade, o audit delay pode ter aumentado, pois o processo de elaboração e auditoria das demonstrações ficou muito mais complexo. Exige mais tempo dos profissionais para incorporar as normas contábeis internacionais às práticas contábeis brasileiras.

Diante do exposto, considerando a necessidade cada vez mais intensa do disclosure ter credibilidade e atender à expectativa de seus usuários e o tempo necessário para publicação do relatório do auditor independente, elabora-se a seguinte questão de pesquisa: Qual a relação entre a republicação das demonstrações contábeis e o audit delay? Desse modo, o objetivo do presente estudo é verificar a relação entre a republicação das demonstrações contábeis e o audit delay.

$\mathrm{Na}$ perspectiva teórica, a pesquisa contribui com estudo sobre a republicação das demonstrações contábeis e o audit delay, principalmente na esfera brasileira, em que a discussão sobre a temática é incipiente. Angeli (2008) destaca que a investigação desse assunto é uma contribuição acadêmica muito importante para um problema real do mercado acionário brasileiro, porém pouco abordado na literatura nacional.

Sob o aspecto empírico, Dantas et al. (2011) elucidam que esse mapeamento pode contribuir para a compreensão de eventuais problemas na elaboração das demonstrações contábeis das empresas integrantes do mercado de capitais brasileiro. A pesquisa pode ajudar a identificar erros cometidos na elaboração das demonstrações contábeis ou até fraudes. As empresas podem ponderar melhor suas informações, o que consequentemente resultará em demonstrações contábeis de maior qualidade e, logo, em reduzir o audit delay.

Do ponto de vista social, a pesquisa pode ser oportuna para investidores que avaliarão melhor as empresas nas quais pretendem investir ou já investem, na ótica de avaliar se a republicação das demonstrações contábeis tem ligação com o audit delay, buscando credibilidade no mercado de ações.

\section{REFERENCIAL TEÓRICO}

\subsection{Republicação das demonstrações contábeis}

As demonstrações contábeis constituem-se em uma das principais fontes para a tomada de decisão dos investidores, credores e outros usuários das informações contábeis 
(Chen, Goo \& Shen, 2014). No Brasil, conforme estabelece a Lei no 6.404 (Lei no 6.404, 1976), ao final de cada exercício social, as companhias de capital aberto devem divulgar as demonstrações contábeis, complementadas por notas explicativas, o Relatório da Administração, bem como o Relatório dos Auditores Independentes sobre as Demonstrações Contábeis. As referidas informações devem ser divulgadas até um mês antes da realização da assembleia geral ordinária e entregues à Comissão de Valores Mobiliários na data em que forem colocadas à disposição do público (Comissão de Valores Mobiliários, 2018).

Referindo-se às informações divulgadas pelas empresas, a importância da fiscalização por um órgão regulador para garantir uma evidenciação justa e apropriada é essencial para disciplinar o processo de divulgação. A Comissão de Valores Mobiliários (CVM) é o órgão que assume esse papel no Brasil (Dantas et al., 2011).

As demonstrações elaboradas de forma neutra buscam retratar integralmente a situação econômica, financeira e patrimonial da empresa. Mas, em alguns casos, os responsáveis pela divulgação dessas demonstrações optam por manipular as informações contábeis, visando ao interesse da entidade e/ou a seus próprios interesses. Consequentemente, podem levar os usuários externos a julgamentos enviesados (Murcia \& Carvalho, 2007).

Mesmo com a atuação da auditoria independente e da fiscalização da CVM, muitas empresas do mercado de capitais omitem ou divulgam informações enviesadas. É necessária a intervenção da CVM, exigindo, em alguns casos, o refazimento e a republicação das demonstrações contábeis (Murcia \& Borba, 2005).

$\mathrm{He}$ e Chiang (2013) explicam que as republicações consistem na reelaboração e divulgação das informações contábeis quando são identificados erros ou omissões materiais após a divulgação e publicação das demonstrações contábeis. Essas republicações podem ocorrer de forma espontânea ou de ofício (Marques, Amaral, Souza, Santos, \& Rodrigues, 2017).

Em relação à necessidade de refazer e republicar as demonstrações contábeis, Netto e Pereira (2011) explicam que, quando há mudança de políticas contábeis e correção de erros, os ajustes devem ser lançados nos resultados acumulados e é necessário reapresentar as demonstrações passadas afetadas por esses ajustes. Porém, quando a mudança de política contábil é proveniente de uma nova norma e essa dispuser de maneira diferente, deve-se agir de acordo com as disposições dessa nova norma. Já, quanto às mudanças de estimativas contábeis, não é necessário reapresentar as demonstrações e os ajustes devem ser lançados no resultado do período em que foi efetuada a mudança.

Teixeira et al. (2013) explicam que sem afetar republicação/redivulgação corrige informações enviesadas, confusas ou incompletas, sem afetar a situação patrimonial. Já o refazimento inclui registros não realizados (provisões, erros em estimativas contábeis, classificação incoerente das contas contábeis), que alteram a situação patrimonial da empresa e que geralmente é acompanhado da republicação que ocorre em virtude de exigência da CVM.

De acordo com Dantas et al. (2011), a CVM fiscaliza a publicação dos relatórios trimestrais e anuais, regula a atuação dos diversos agentes e também pune atos que estão em desacordo com as normas e regulamentos. A determinação de republicação das demonstrações contábeis somente é oportuna quando essas demonstrações apresentarem erros e/ou forem insuficientes para um bom entendimento.

Quando uma empresa de capital aberto enviesa ou omite uma informação, a CVM emite um ofício de notificação determinando a elaboração das correções necessárias dos erros ou inconsistências e a republicação da demonstração correspondente. A Deliberação CVM no $388 / 2001$ permite a divulgação do inteiro teor dos ofícios de notificação, viabilizando aos investidores e ao público em geral conhecer as causas do refazimento e republicação das demonstrações dessas empresas. A divulgação dos ofícios de notificação é feita no sitio eletrônico da CVM (Dantas et al., 2011).

Conforme Bills, Swanquist e Whited (2016), a republicação das demonstrações contábeis é entendida como um indicador da qualidade das demonstrações e da qualidade da auditoria. Nesse sentido, a republicação pode ser um indicativo da baixa qualidade das demonstrações publicadas anteriormente, bem como pode sugerir uma menor qualidade da 
auditoria, visto que essa não foi capaz de detectar de forma oportuna os possíveis erros ou inconsistências existentes. Assim, uma auditoria de maior qualidade deve ser capaz de detectar mais erros, o que resulta em um número menor de republicações (Ettredge, Fuerherm \& Li, 2014). De acordo com Bischoff, Finley e Leblanc (2008), o mercado de ações tende a reagir negativamente à notícia de refazimento, pois dá aos investidores a impressão de que a gestão está tentando fraudar as informações intencionalmente ou que é incapaz de elaborar demonstrações com qualidade. Por esse motivo, a republicação de demonstrações contábeis é um dos pontos principais no debate a respeito da qualidade das informações contábeis divulgadas ao mercado (Romanus, Maher, \& Fleming, 2008).

Entre os principais motivos para o refazimento e republicação das demonstrações estão: reconhecimento indevido de receitas e despesas, reconhecimento das remunerações baseadas em ações, erros de classificação de contas contábeis e o fato das empresas evitarem a divulgação de reformulações das demonstrações (Bischoff et al., 2008).

A confiança no mercado de capitais depende do nível de confiança que os investidores depositam nas demonstrações contábeis ao tomar decisões de investimento. Por isso o papel dos auditores em garantir a qualidade das demonstrações contábeis vem ganhando mais atenção nos últimos tempos (Romanus et al., 2008).

\subsection{Audit Delay}

Conforme a Norma Brasileira de Contabilidade NBC TA 200 (R1) (Conselho Federal de Contabilidade [CFC], 2016a), o objetivo da auditoria é aumentar o grau de confiança nas demonstrações contábeis por parte dos usuários, mediante a expressão de uma opinião pelo auditor sobre se essas demonstrações foram elaboradas em conformidade com uma estrutura de relatório financeiro aplicável. Nesse contexto, pode-se afirmar que o auditor assume papel relevante na redução da assimetria das informações, por meio da opinião expressa em seu relatório.

No Brasil todas as companhias abertas e as sociedades de grande porte devem ter suas demonstrações contábeis auditadas por um profissional independente registrado na CVM. A Resolução no 953/03 do CFC e a Instrução n 308/99 da CVM estabelecem que os auditores independentes devem emitir opinião sobre a adequação da empresa a respeitadas práticas contábeis adotadas no país, em um determinado período (Damascena, Firmino \& Paulo, 2011).

O relatório do auditor independente é o documento no qual ele expressa sua opinião, de forma clara e objetiva, se as demonstrações auditadas estão adequadamente representadas ou não, dirigindo-se a cotistas, acionistas ou sócios, ao conselho de administração ou à diretoria da entidade. Por meio do relatório o auditor assume a responsabilidade técnicoprofissional, sendo indispensável que tal documento obedeça às características inerentes estabelecidas pelas normas competentes (Dantas et al., 2011).

Damascena et al. (2011) consideram que o relatório é a peça materializada de todo o trabalho realizado pela auditoria. Conforme a NBC TA 705 (CFC, 2016b), o relatório do auditor independente classifica-se, de acordo com a natureza da opinião expressa, em dois tipos principais: opinião não modificada e opinião modificada (com ressalva, adversa ou com abstenção de opinião).

A opinião não modificada indica que as demonstrações contábeis da empresa auditada foram elaboradas de acordo com as normas e práticas vigentes no Brasil; a opinião modificada com ressalva ocorre quando o auditor conclui que o efeito de qualquer discordância ou restrição poderá afetar as demonstrações contábeis; a opinião modificada adversa revela que as demonstrações contábeis estão em desacordo com as normas e práticas adotadas no país e a abstenção ou negativa de opinião acontece quando o auditor não consegue emitir opinião por não obter confirmação de informações para fundamentá-la (Damascena et al., 2011).

Outro fator relevante dentro do relatório do auditor independente é o parágrafo de ênfase e de outros assuntos. Segundo a NBC TA 706 (CFC, 2016c), o parágrafo de ênfase irá relatar informações corretamente apresentadas dentro das demonstrações contábeis, mas que o auditor julga ter importância fundamental para o entendimento dos usuários das demonstrações. Cabe ressaltar que o parágrafo de ênfase não altera o tipo de opinião expressa pelo auditor. O audit delay, também denominado audit report lag, é o número de dias 
transcorrido entre o final do exercício social e a data de emissão do relatório do auditor (O'Sullivan, 2000; Knechel \& Sharma, 2012).

Pereira (2011) também considera que se o audit delay é elevado pode significar que a empresa apresente problemas nas demonstrações contábeis, o que pode comprometer o prazo da entrega do relatório do auditor independente e haver um agrave na percepção de risco de informação no desempenho das empresas, afetando a tomada de decisão. Os investidores podem querer vender as ações ou exigir maior remuneração, já os conselheiros da administração das empresas podem querer trocar de auditor.

Dantas et al. (2011) afirmam que, quanto maior for a qualidade dos trabalhos desenvolvidos pela auditoria, maior será sua eficácia, pois a auditoria é um instrumento essencial de fornecimento de confiança aos investidores e demais usuários das informações divulgadas pelas entidades. Na prática, cada vez que se constata a divulgação e publicação de demonstrações contábeis sem atender aos requisitos de divulgação adequada, justa e plena, a utilidade dos trabalhos dos auditores é intensamente questionada (Dantas et al. 2011).

\section{METODOLOGIA}

\subsection{Delineamento da pesquisa, população e amostra}

Tendo como menção o objetivo do presente trabalho, que é analisar a relação entre a republicação das demonstrações contábeis com o audit delay, pode-se classificar este estudo como uma pesquisa descritiva, com abordagem quantitativa, realizada por meio de pesquisa documental. Para Gil (1999), as pesquisas descritivas têm como objetivo a descrição das características de determinada população ou fenômeno ou, então, o estabelecimento de relações entre variáveis.

Sob o aspecto dos procedimentos técnicos utilizados, tem-se uma pesquisa documental. Para Martins e Theóphilo (2009), a pesquisa documental é caracterizada pela utilização de documentos como fonte de dados, informação e evidências. Os autores ainda relatam que a pesquisa documental emprega materiais compilados pelo próprio autor do trabalho, que ainda não foram objeto de análise, ou que ainda podem ser reelaborados de acordo com os propósitos da pesquisa. Nesse sentido, o presente trabalho caracteriza-se como pesquisa do tipo documental, tendo em vista que os dados utilizados advêm do sítio da BM\&FBovespa, no qual os dados coletados são publicados a diversos usuários.

Sob o aspecto da abordagem do problema, esta pesquisa está classificada como quantitativa. Para Raupp e Beuren (2003), o método quantitativo tem como principal característica o emprego de instrumentos estatísticos na coleta e tratamento dos dados. Este estudo caracteriza-se como quantitativo pelo fato de utilizar métodos estatísticos na coleta de dados. Esses dados são retirados do formulário de referência no sítio da BM\&FBovespa e tabulados em planilha eletrônica para posterior análise.

A população do presente trabalho é definida pelas 495 empresas listadas na BM\&FBovespa, separadas por setores: 37 empresas do setor de Bens Industriais, 71 de Construção e Transporte, 66 de Consumo Cíclico, 39 de Consumo Não-Cíclico, 139 de Financeiro e Outros, 38 de Materiais Básicos, 12 de Petróleo, Gás e Biocombustíveis, 10 de Tecnologia da Informação, 8 de Telecomunicações e 75 de Utilidade Pública.

De um total de 495 empresas listadas na BM\&FBovespa, foram selecionadas para a pesquisa as empresas que apresentaram o Relatório do Auditor Independente sobre as Demonstrações Contábeis da companhia, entre os anos de 2011 e 2016. A amostra final é composta por 446 empresas selecionadas no período de 2011, 463 empresas em 2012, 465 empresas no ano 2013, 462 empresas em 2014, 404 empresas em 2015 e 416 companhias em 2016, conforme se observa na Tabela 1. 
Tabela 1

Número de empresas por setor de atuação selecionadas para análise em cada período

\begin{tabular}{|c|c|c|c|c|c|c|c|c|c|c|c|c|}
\hline \multirow[b]{2}{*}{ Setor de Atuação } & \multicolumn{2}{|c|}{2011} & \multicolumn{2}{|c|}{2012} & \multicolumn{2}{|c|}{2013} & \multicolumn{2}{|c|}{2014} & \multicolumn{2}{|c|}{2015} & \multicolumn{2}{|c|}{2016} \\
\hline & $\mathbf{N}$ & $\%$ & $\mathbf{N}$ & $\%$ & $\mathbf{N}$ & $\%$ & $\mathbf{N}$ & $\%$ & $\mathbf{N}$ & $\%$ & $\mathbf{N}$ & $\%$ \\
\hline Bens Industriais & 33 & 7,4 & 34 & 7,3 & 34 & 7,3 & 32 & 6,9 & 32 & 7,9 & 37 & 8,9 \\
\hline Construção e Transporte & 64 & 14,3 & 68 & 14,7 & 71 & 15,3 & 68 & 14,7 & 51 & 12,6 & 51 & 12,3 \\
\hline Consumo Cíclico & 60 & 13,5 & 62 & 13,4 & 63 & 13,5 & 63 & 13,6 & 61 & 15,1 & 65 & 15,6 \\
\hline Consumo Não-Cíclico & 30 & 6,7 & 33 & 7,1 & 33 & 7,1 & 33 & 7,1 & 29 & 7,2 & 30 & 7,2 \\
\hline Financeiro e Outros & 129 & 28,9 & 135 & 29,2 & 135 & 29,0 & 135 & 29,2 & 111 & 27,5 & 112 & 26,9 \\
\hline Materiais Básicos & 37 & 8,3 & 37 & 8,0 & 36 & 7,7 & 36 & 7,8 & 32 & 7,9 & 32 & 7,7 \\
\hline Petróleo, Gás e Biocombustível & 5 & 1,1 & 5 & 1,1 & 6 & 1,3 & 6 & 1,3 & 11 & 2,7 & 12 & 2,9 \\
\hline Tecnologia da Informação & 9 & 2,0 & 10 & 2,2 & 9 & 1,9 & 10 & 2,2 & 7 & 1,7 & 7 & 1,7 \\
\hline Telecomunicações & 8 & 1,8 & 8 & 1,7 & 8 & 1,7 & 8 & 1,7 & 5 & 1,2 & 5 & 1,2 \\
\hline Utilidade Pública & 71 & 15,9 & 71 & 15,3 & 70 & 15,1 & 71 & 15,4 & 65 & 16,1 & 65 & 15,6 \\
\hline Total & 446 & $100 \%$ & 463 & $100 \%$ & 465 & $100 \%$ & 462 & $100 \%$ & 404 & $100 \%$ & 416 & $\begin{array}{c}100 \\
\%\end{array}$ \\
\hline
\end{tabular}

Fonte: Dados da pesquisa.

Como se observa na Tabela 1, a maior amostra (465) está concentrada no ano de 2013. O setor que possui o maior número de empresas é o "Financeiro e Outros" com 135 empresas, o que representa $29 \%$ da amostra do período. Em seguida o setor que comporta maior número de empresas é o de "Construção e Transporte" (15,3\%) com 71 empresas, seguido do setor de "Utilidade Pública" (15,1\%) com 70 empresas.

A escolha do lapso temporal (de 2011 a 2016) deu-se em função de que anteriormente a 2011 as companhias ainda estavam em processo de convergência ao padrão IFRS, o que poderia dilatar o audit delay além do usual. Salienta-se que o ano de 2017 não foi contemplado na análise, pois muitas empresas ainda não haviam divulgado as demonstrações contábeis quando se realizou a coleta de dados.

\subsection{Constructo da pesquisa}

Martins e Theóphilo (2009, p. 35) explicam que "para explorar empiricamente um conceito teórico, o pesquisador precisa traduzir a assertiva genérica do conceito em uma relação com o mundo real, baseado em variáveis e fenômenos observáveis e mensuráveis". Os autores ainda orientam que para buscar a solução de um problema, o pesquisador deve esclarecer de maneira precisa os significados dos termos principais, conceitos, definições e constructos, que serão abordados na pesquisa. Dessa maneira, elaborou-se na Tabela 2 o constructo deste trabalho, considerando os objetivos específicos e as variáveis de estudo.

Tabela 2

Constructo da pesquisa

\begin{tabular}{l|l|l}
\hline \multicolumn{1}{c|}{ Variável } & \multicolumn{1}{|c}{ Operacionalização } & \multicolumn{1}{c}{ Local de Coleta } \\
\hline $\begin{array}{l}\text { Republicação } \\
\text { Demonstrações } \\
\text { Contábeis }\end{array}$ & $\begin{array}{l}\text { Republicações realizadas e publicadas no sítio } \\
\text { da BM\&FBovespa sendo "1" republicação e "0" } \\
\text { publicação. }\end{array}$ & $\begin{array}{l}\text { Demonstrações Contábeis das } \\
\text { empresas publicadas no sítio da } \\
\text { BM\&FBovespa. }\end{array}$ \\
\hline $\begin{array}{l}\text { Audit Delay } \\
\text { Diferença em dias, entre a data de encerramento } \\
\text { do exercício e a data de emissão do relatório do do } \\
\text { auditor independente. }\end{array}$ & $\begin{array}{l}\text { Demonstrações Contábeis das } \\
\text { empresas publicadas no sítio da } \\
\text { BM\&FBovespa. }\end{array}$ \\
\hline
\end{tabular}

Fonte: Dados da pesquisa.

Destaca-se que nesta pesquisa não se levou em consideração o motivo da republicação da demonstração. Logo, foram levadas em consideração na análise todas as demonstrações republicadas, independentemente de serem objeto de refazimento ou não.

\subsection{Coleta e análise dos dados}

Inicialmente foi utilizado o sítio da BM\&FBovespa para pesquisar e coletar todas as empresas que estão listadas. A partir daí iniciou-se então a coleta de dados quanto ao audit delay e à republicação dessas empresas. Os dados foram coletados nos relatórios financeiros divulgados no sítio da BM\&FBovespa. Selecionou-se o ano desejado e foram coletados os 
dados referentes à modalidade (publicação ou republicação), a data de recebimento das Demonstrações e à data do Relatório dos Auditores Independentes.

Todos os dados foram coletados e tabulados em planilha eletrônica. Visando ao objetivo geral da pesquisa, que é verificar a relação entre a republicação das demonstrações contábeis e o audit delay, procedeu-se à análise dos dados. Para tanto, utilizou-se estatística descritiva, testes de média e teste de correlação, calculados por meio do software Statistical Package for the Social Sciences® (SPSS).

Para Magalhães e Lima (2005), a estatística descritiva é utilizada quando se inicia contato com os dados pela primeira vez. Fávero, Belfiore, Silva e Chan (2009) complementam que a estatística descritiva permite ao investigador uma melhor compreensão do comportamento dos dados, por meio de tabelas, gráficos e medidas. Identifica tendências, variabilidade e valores atípicos.

O teste de diferença de médias tem por objetivo determinar se há diferença estatisticamente significativa entre as médias de dois grupos (Field, 2009). Nesse caso, analisou-se se a média de audit delay das empresas que tiveram republicação é significativamente diferente da média das empresas que não tiveram republicação.

Antes de proceder ao teste de diferença de médias, efetuou-se a análise da normalidade dos dados, por meio do teste Kolmogorov-Smirnov. Sempre que o valor de significância apresentado nesses testes for menor que 0,05 , os dados não apresentam distribuição normal, ao passo que se o resultado for maior que 0,05 há indícios que os dados apresentam distribuição normal (Field, 2009).

Conhecer de que modo os dados se apresentam distribuídos é necessário, pois dependendo do tipo de distribuição, testes diferentes deverão ser empregados. Desse modo, quando os dados apresentam distribuição normal empregam-se testes paramétricos, ao passo que se a distribuição amostral for não normal devem ser aplicados testes não-paramétricos (Field, 2009). Os resultados dos testes de normalidade revelaram que a distribuição difere significativamente de uma divisão normal, conforme se pode observar na Tabela 3.

Tabela 3

Teste de normalidade dos dados

\begin{tabular}{c|l|c|c|c}
\hline \multirow{2}{*}{ Ano Grupo } & \multicolumn{3}{c}{ Kolmogorov-Smirnov } \\
\cline { 3 - 5 } & & Estatística & df & Sig. \\
\hline \multirow{2}{*}{2011} & Publicação & 0,306 & 292 & 0,000 \\
\cline { 2 - 5 } & Republicação & 0,374 & 154 & 0,000 \\
\hline \multirow{2}{*}{2012} & Publicação & 0,197 & 301 & 0,000 \\
\cline { 2 - 5 } & Republicação & 0,368 & 162 & 0,000 \\
\hline \multirow{2}{*}{2013} & Publicação & 0,250 & 338 & 0,000 \\
\cline { 2 - 5 } & Republicação & 0,241 & 127 & 0,000 \\
\hline \multirow{2}{*}{2014} & Publicação & 0,152 & 355 & 0,000 \\
\cline { 2 - 5 } & Republicação & 0,177 & 107 & 0,000 \\
\hline \multirow{2}{*}{2015} & Publicação & 0,125 & 312 & 0,000 \\
\cline { 2 - 5 } & Republicação & 0,367 & 92 & 0,000 \\
\hline \multirow{2}{*}{2016} & Publicação & 0,322 & 319 & 0,000 \\
\cline { 2 - 5 } & Republicação & 0,296 & 97 & 0,000 \\
\hline
\end{tabular}

Fonte: Dados da pesquisa.

Analisando-se a Tabela 3 observa-se que todos os testes foram significativos ao nível de $5 \%$, o que indica que os dados não se apresentam normalmente distribuídos. Dessa forma, na análise dos dados, adotou-se o teste não-paramétrico de Mann-Whitney para testar a diferença de médias existente entre os grupos.

O teste não-paramétrico de Mann-Whitney é usado para testar se duas amostras independentes provêm de populações com médias iguais. Baseia-se na disposição dos dados em postos e não faz a exigência de a população ter a mesma variância, somente que o nível da mensuração esteja numa escala contínua (Stevenson, 2001).

Por fim, de modo a testar a relação existente entre as duas variáveis pesquisadas, efetuou-se o teste de correlação. A correlação é uma técnica associativa utilizada para 
determinar se há relação coerente e sistemática entre duas ou mais variáveis (Hair, Babin, Money, \& Samouel, 2005).

\section{ANÁLISE DOS RESULTADOS}

\subsection{Publicação e republicação das demonstrações contábeis}

Primeiramente, buscou-se distinguir as empresas listadas na BM\&FBovespa que publicaram suas demonstrações apenas uma vez, daquelas que por algum motivo republicaram suas demonstrações contábeis no período de análise. A Tabela 4 demonstra a segregação das empresas que tiveram republicação ou que não tiveram republicação por período analisado.

Tabela 4

Número de empresas com publicação e republicação, por ano

\begin{tabular}{|c|c|c|c|c|c|c|c|c|c|c|c|c|c|c|}
\hline & \multicolumn{2}{|c|}{2011} & \multicolumn{2}{|c|}{2012} & \multicolumn{2}{|c|}{2013} & \multicolumn{2}{|c|}{2014} & \multicolumn{2}{|c|}{2015} & \multicolumn{2}{|c|}{2016} & \multicolumn{2}{|c|}{ Total } \\
\hline & $\mathbf{N}$ & $\%$ & $\mathbf{N}$ & $\%$ & $\mathbf{N}$ & $\%$ & $\mathbf{N}$ & $\%$ & $\mathbf{N}$ & $\%$ & $\mathbf{N}$ & $\%$ & $\mathbf{N}$ & $\%$ \\
\hline Publicação & 292 & 65,5 & 301 & 65,1 & 338 & 72,7 & 355 & 76,8 & 312 & 77,2 & 319 & 76,7 & 1917 & 72,2 \\
\hline Republicação & 154 & 34,5 & 162 & 34,9 & 127 & 27,3 & 107 & 23,2 & 92 & 22,8 & 97 & 23,3 & 739 & 27,8 \\
\hline Total & 446 & $100 \%$ & 463 & $100 \%$ & 465 & $100 \%$ & 462 & $100 \%$ & 404 & $100 \%$ & 416 & $100 \%$ & 2656 & $100 \%$ \\
\hline
\end{tabular}

Fonte: Dados da pesquisa.

Analisando a Tabela 4, percebe-se que no período de 2012 houve maior incidência de republicações, correspondendo a $34,9 \%$ do total de 463 empresas classificadas para a análise. No ano de 2011, do total de 446 empresas, 154 republicaram suas demonstrações contábeis, representando $34,5 \%$. Esse fato pode estar relacionado com o processo de convergência às normas internacionais de contabilidade introduzidos pela Lei 11.638/07. No entanto, destaca-se que 2008 foi o primeiro ano com reais influências da referida lei. Teixeira et al. (2013) destacam que o fato de os casos de refazimento se estenderem, indicam prováveis dificuldades das empresas em se adequarem às novas normas contábeis.

No entanto, ainda analisando a Tabela 3, com o passar dos anos observa-se a redução dos casos de republicação, pois em 2011 houve 34,5\% enquanto que em 2016 observa-se apenas $23,3 \%$ do total de demonstrações republicadas. Isso pode indicar que as empresas estão se empenhando em divulgar suas demonstrações contábeis dentro das normas. Conforme Dantas et al. (2011), a determinação de refazimento e republicação das demonstrações contábeis deveria ser evitada, de modo a manter a sua integridade e assim fornecer aos usuários informações sobre a situação patrimonial e financeira, e para servir de apoio em suas decisões.

A identificação das empresas listadas na BM\&FBovespa foi realizada observando-se os segmentos em que todas estão enquadradas, que totalizam 10 setores. A Tabela 5 demonstra a quantidade de publicações e republicações das demonstrações contábeis por setor em todo o período da análise.

Tabela 5

Publicações e Republicações por setor, no período de 2011 a 2016

\begin{tabular}{l|c|c|c|c}
\hline \multicolumn{1}{c|}{ Setor de Atuação } & Publicação & Republicação & Total & $\%$ \\
\hline Bens Industriais & 158 & 44 & 202 & $7,6 \%$ \\
\hline Construção e Transporte & 277 & 96 & 373 & $14,0 \%$ \\
\hline Consumo Cíclico & 265 & 109 & 374 & $14,1 \%$ \\
\hline Consumo Não-Cíclico & 139 & 49 & 188 & $7,1 \%$ \\
\hline Financeiro e Outros & 548 & 209 & 757 & $28,5 \%$ \\
\hline Materiais Básicos & 157 & 53 & 210 & $7,9 \%$ \\
\hline Petróleo, Gás e Biocombustível & 31 & 14 & 45 & $1,7 \%$ \\
\hline Tecnologia da Informação & 36 & 16 & 52 & $2,0 \%$ \\
\hline Telecomunicações & 32 & 10 & 42 & $1,6 \%$ \\
\hline Utilidade Pública & 274 & 139 & 413 & $15,5 \%$ \\
\hline Total & $\mathbf{1 9 1 7}$ & $\mathbf{7 3 9}$ & $\mathbf{2 6 5 6}$ & $\mathbf{1 0 0} \%$ \\
\hline
\end{tabular}

Fonte: Dados da pesquisa. 
Observa-se na Tabela 5 que o setor com maior representatividade é o "Financeiro e Outros" com $28,5 \%$ do total de 2656 observações analisadas. Esse resultado já era esperado, em função de ser esse o setor que compreende o maior número de empresas da amostra estudada. O setor de "Utilidade Pública" aparece logo em seguida com 15,5\%, seguido pelo setor "Consumo Cíclico" com 14,1\%.

A Tabela 6 refere-se à quantidade de republicações que ocorreram em cada setor em todos os anos analisados.

Tabela 6

Número de republicações por setor no período de 2011 a 2016

\begin{tabular}{|c|c|c|c|c|c|c|c|c|c|c|c|c|c|c|}
\hline \multirow{2}{*}{ Setor de Atuação } & \multicolumn{2}{|c|}{2011} & \multicolumn{2}{|c|}{2012} & \multicolumn{2}{|c|}{2013} & \multicolumn{2}{|c|}{2014} & \multicolumn{2}{|c|}{2015} & \multicolumn{2}{|c|}{2016} & \multicolumn{2}{|c|}{ Total } \\
\hline & $\mathbf{N}$ & $\%$ & $\mathbf{N}$ & $\%$ & $\mathbf{N}$ & $\%$ & $\mathbf{N}$ & $\%$ & $\mathbf{N}$ & $\%$ & $\mathbf{N}$ & $\%$ & $\mathbf{N}$ & $\%$ \\
\hline Bens Industriais & 9 & 5,8 & 10 & 6,2 & 11 & 8,7 & 3 & 2,8 & 3 & 3,3 & 8 & 8,2 & 44 & 6,0 \\
\hline Construção Transporte & 25 & 16,2 & 25 & 15,4 & 16 & 12,6 & 11 & 10,3 & 9 & 9,8 & 11 & 11,3 & 97 & 13,1 \\
\hline Consumo Cíclico & 20 & 13,0 & 21 & 13,0 & 19 & 15,0 & 15 & 14,0 & 18 & 19,6 & 15 & 15,5 & 108 & 14,6 \\
\hline Consumo não-cíclico & 7 & 4,5 & 13 & 8,0 & 12 & 9,4 & 5 & 4,7 & 4 & 4,3 & 8 & 8,2 & 49 & 6,6 \\
\hline Financeiro e Outros & 37 & 24,0 & 49 & 30,2 & 33 & 26,0 & 39 & 36,4 & 27 & 29,3 & 24 & 24,7 & 209 & 28,3 \\
\hline Materiais Básicos & 15 & 9,7 & 8 & 4,9 & 13 & 10,2 & 10 & 9,3 & 1 & 1,1 & 6 & 6,2 & 53 & 7,2 \\
\hline $\begin{array}{l}\text { Petróleo, Gás e } \\
\text { Biocombustível }\end{array}$ & 4 & 2,6 & 1 & 0,6 & 2 & 1,6 & 1 & 0,9 & 3 & 3,3 & 3 & 3,1 & 14 & 1,9 \\
\hline Tecnologia da Informação & 6 & 3,9 & 4 & 2,5 & 0 & 0,0 & 4 & 3,7 & 2 & 2,2 & 0 & 0,0 & 16 & 2,2 \\
\hline Telecomunicação & 4 & 2,6 & 4 & 2,5 & 0 & 0,0 & 1 & 0,9 & 0 & 0,0 & 1 & 1,0 & 10 & 1,4 \\
\hline Utilidade Pública & 27 & 17,5 & 27 & 16,7 & 21 & 16,5 & 18 & 16,8 & 25 & 27,2 & 21 & 21,6 & 139 & 18,8 \\
\hline Total & 154 & 100 & 162 & 100 & 127 & 100 & 107 & 100 & 92 & 100 & 97 & 100 & 739 & 100 \\
\hline
\end{tabular}

Fonte: Dados da pesquisa.

Como se observa na Tabela 6, o setor "Financeiro e outros" tem a maior porcentagem de participação nas reapresentações em todos os anos, 24\%, 30,2\%, 26\%, 36,4\%, 29,3\% e $24,7 \%$, respectivamente. Isso se deve ao fato de apresentar maior participação na pesquisa, como se pode averiguar na Tabela 5. Observa-se ainda que as republicações, de forma geral, seguiram uma tendência de redução de casos ao longo do período analisado. Entretanto, em alguns setores de atuação, tal tendência foi interrompida nos anos de 2015 e 2016, como é demonstrado na Tabela 6 , para os setores de bens industriais, construção e transportes, consumo cíclico e não cíclico, financeiro, petróleo, gás e biocombustível e utilidade pública.

De acordo com Murcia e Carvalho (2007), os responsáveis pela divulgação das demonstrações contábeis no mercado de capitais, em alguns casos omitem ou divulgam informações manipuladas, visando ao interesse da empresa ou até a interesses próprios, que podem levar os usuários externos a julgamentos errados. Nesses casos, a CVM intervém exigindo o refazimento e republicação das demonstrações contábeis.

\subsection{Audit Delay nas empresas investigadas}

A análise de audit delay é realizada utilizando-se a estatística descritiva com o auxílio do software SPSS $\AA$. Desse modo, analisou-se a média e os valores máximos e mínimos de dias para entrega do relatório. A Tabela 7 apresenta essas médias, em dias, para o audit delay de maneira geral, para as publicações e as republicações por ano.

Tabela 7

Identificação do audit delay das publicações e republicações por ano

\begin{tabular}{c|c|c|c|c|c|c}
\hline \multirow{2}{*}{ Ano } & \multicolumn{3}{|c|}{ Publicação } & \multicolumn{3}{c}{ Republicação } \\
\cline { 2 - 7 } & Mínimo & Máximo & Média & Mínimo & Máximo & Média \\
\hline 2011 & 19 & 639 & 72 & 23 & 816 & 109 \\
\hline 2012 & 15 & 238 & 68 & 22 & 690 & 95 \\
\hline 2013 & 10 & 525 & 69 & 34 & 318 & 72 \\
\hline 2014 & 9 & 210 & 68 & 26 & 133 & 67 \\
\hline 2015 & 14 & 218 & 69 & 26 & 697 & 160 \\
\hline 2016 & 19 & 405 & 77 & 20 & 331 & 93 \\
\hline
\end{tabular}

Fonte: Dados da pesquisa. 
O audit delay é representado pelo número de dias entre a data de encerramento do exercício e a emissão do relatório de auditoria independente. Segundo Pereira (2011), quanto maior o audit delay, pior é para a empresa, pois isso é analisado sob a probabilidade de que a empresa está com problemas. Por essa razão a demora em os auditores entregarem o seu relatório. Para a presente pesquisa, na definição de Pereira (2011), utiliza-se o conceito de que um audit delay "bom" é um audit delay pequeno, ou seja, quanto menor o atraso na entrega do relatório, melhor.

$\mathrm{Na}$ amostra selecionada, percebe-se que das empresas que não tiveram republicação das demonstrações contábeis apenas uma vez, o menor audit delay foi de 9 dias, no período de 2014, enquanto que o maior prazo está em 2011 com o máximo de 639 dias para emissão do parecer. Já nas empresas que tiveram suas demonstrações republicadas, o menor audit delay é de 20 dias em 2016 e o maior prazo de 816 dias está em 2011.

Porém, ao comparar somente as médias do audit delay, o menor prazo entre as publicações ficou praticamente igual em 2012, 2013 e 2014, com a média de 68 dias. Restam 2015 com a média de 69 dias, 2011 com a média de 72 dias e 2016 com média de 77 dias. No entanto, no grupo de republicações a menor média foi de 67 dias em 2014 e em 2015 observou-se a maior média, com 160 dias de audit delay.

Observa-se que o aumento do audit delay seguiu a tendência apresentada na Tabela 6. Nos anos de 2015 e 2016 obteve-se o aumento de republicações. Nesses anos (2015 e 2016), conforme demonstrado na Tabela 7, o audit delay voltou a aumentar, como se observa nos valores mínimos, máximos e média.

Destaca-se que o estudo de Camargo e Flach (2016) encontrou um audit delay médio para o ano de 2013, inferior ao encontrado neste estudo. Os autores encontraram que o número de dias para o recebimento do relatório de auditoria para as empresas da amostra estudada é de 60 dias, enquanto este estudo reportou um prazo médio de 69 dias para 0 mesmo período. Porém, deve-se salientar que a amostra utilizada por Camargo e Flach (2016) considerou apenas empresas que negociam no $\mathrm{IBrX} 100$, o que pode ter levado a essa diferença.

Da análise da Tabela 7 pode-se notar que, com exceção de 2014, todos os anos restantes apresentam menor audit delay médio no grupo que publicou as demonstrações contábeis apenas uma vez. A seguir essa diferença é analisada de forma mais minuciosa, por meio do teste de diferença de médias e do teste de correlação.

\subsection{Relação entre a republicação e o Audit Delay}

A fim de atingir o objetivo proposto, ou seja, verificar a relação entre a republicação das demonstrações contábeis e o audit delay, efetuou-se primeiramente o teste de diferença de médias, a fim de identificar se a média de dias de audit delay das empresas com republicação é significativamente diferente da média das empresas sem republicação. Por fim, é realizada a análise de correlação entre as duas variáveis da pesquisa.

Primeiramente foi realizada a análise para o ano de 2011. Para avaliar a diferença de médias utilizou-se o teste de Mann-Whitney. No período analisado a amostra compreendeu 446 empresas que apresentaram todas as informações necessárias para análise. Desse total de empresas, 292 não republicaram suas demonstrações, enquanto as restantes 154 tiveram demonstrações republicadas. Analisando-se a média de cada grupo percebe-se que a de audit delay das publicações das demonstrações foi de 72 dias, ao passo que a média de audit delay das empresas com republicações, foi de 109 dias. Desse modo, há indícios de que as médias observadas provêm de dois grupos distintos. Para comprovar tal fato, procedeu-se ao teste de Mann-Whitney, cujo resultado pode ser verificado na Tabela 8. 
Tabela 8

Teste de Mann-Whitney sobre as médias de 2011

\begin{tabular}{lcccc}
\hline Grupo & N & Postos de média & Soma de classificações & Média de Audit Delay \\
\hline Publicação & 292 & 211,28 & 61692,5 & 72 \\
Republicação & 154 & 246,68 & 37988,5 & 109 \\
\hline Total & $\mathbf{4 4 6}$ & & \\
\hline U de Mann-Whitney & & 18914,5 & \\
Wilcoxon W & & 61692,5 & \\
Z & & $-2,759$ & \\
Significância Sig. (2 extremidades) & & 0,006 & \\
\hline
\end{tabular}

Fonte: Dados da pesquisa.

Ao analisar o resultado do teste de Mann-Whitney, percebe-se que esse é significativo ao nível de $5 \%$ (Sig. de 0,006), o que indica que há diferença expressiva entre as médias de audit delay das empresas que republicaram e que publicaram as demonstrações contábeis no ano de 2011. Esse fato fornece indícios de que quanto maior o audit delay, maior a chance de a empresa republicar a demonstração contábil, visto que a média do grupo com republicação foi superior à média do grupo que não a republicou.

Um maior audit delay indica que maior trabalho foi dispensado pelos auditores no processo de análise. Revela a existência de inconsistências nas demonstrações contábeis. Pereira (2011) menciona que, um audit delay elevado pode afetar a tomada de decisão, agravar a percepção de risco no desempenho das empresas e levar os investidores a vender suas ações ou até a exigir maior remuneração.

A amostra do ano de 2012 abrangeu 301 empresas que publicaram suas demonstrações apenas uma vez e 162 que tiveram suas demonstrações contábeis republicadas, assim totalizando a amostra de 463 empresas. Considerando a média de cada grupo, analisa-se que a média de audit delay das empresas que não republicaram as demonstrações foi de 68 dias, enquanto a média de audit delay das empresas com republicação foi de 95 dias. O teste de Mann-Whitney, apresentado na Tabela 9, revela uma diferença significativa entre as médias dos dois grupos.

Tabela 9

Teste de Mann-Whitney sobre as médias de 2012

\begin{tabular}{lcccc}
\hline Grupo & N & Postos de média & Soma de classificações & Média de Audit Delay \\
\hline Publicação & 301 & 215,13 & 64754,0 & 68 \\
Republicação & 162 & 263,35 & 42662,0 & 95 \\
\hline Total & $\mathbf{4 6 3}$ & & \\
\hline U de Mann-Whitney & & 19303,0 & \\
Wilcoxon W & & 64754,0 & \\
Z & & $-3,701$ & \\
Significância Sig. (2 extremidades) & & 0,000 & \\
\hline
\end{tabular}

Fonte: Dados da pesquisa.

O resultado do teste de Mann-Whitney indica um nível de significância de 0,000, que representa uma diferença significativa entre as médias de audit delay das publicações e republicações das demonstrações contábeis no período de 2012. Como a média do grupo de republicações foi maior que a média das empresas que tiveram publicações, isso fortalece os indícios de que um elevado audit delay pode indicar que as demonstrações contábeis dessas empresas podem ser republicadas.

Posteriormente, analisou-se o ano de 2013, que compreendeu uma amostra de 465 empresas. 338 publicaram suas demonstrações apenas uma vez e 127 em algum momento tiveram suas demonstrações republicadas. Apresentou-se uma média de audit delay de 69 dias para as demonstrações contábeis publicadas apenas uma vez e para as republicadas uma média de 72 dias. A diferença entre a média de audit delay dos dois grupos analisados é pouco expressiva. Para verificar se de fato há diferença estatística, procedeu-se ao teste de MannWhitney, conforme Tabela 10. 
Tabela 10

Teste de Mann-Whitney sobre as médias de 2013

\begin{tabular}{lcccc}
\hline Grupo & $\mathbf{N}$ & Postos de média & Soma de classificações & Média de Audit Delay \\
\hline Publicação & 338 & 228,75 & 77318,5 & 69 \\
Republicação & 127 & 244,30 & 31026,5 & 72 \\
\hline Total & 465 & & & \\
\hline U de Mann-Whitney & & 20027,5 & \\
Wilcoxon W & & 77318,5 & \\
Z & & $-1,112$ & \\
Significância Sig. (2 extremidades) & & 0,266 & \\
\hline
\end{tabular}

Fonte: Dados da pesquisa.

O resultado do teste de Mann-Whitney não apresentou significância (Sig. 0,266). Indica que as médias dos dois grupos analisados não diferem de forma significativa. Mesmo assim, a média das empresas que republicaram suas demonstrações contábeis ficou acima das que não republicaram. Mais uma vez esse fato fortalece os indícios de que um elevado audit delay pode estar ligado à republicação das demonstrações das empresas e indicar inconsistências encontradas pelos auditores.

Pereira e Costa (2012) concluíram em sua pesquisa entre os anos de 1999 e 2008 que existe uma relação positiva entre o audit delay e a ocorrência de ressalvas. O comportamento dos auditores e a utilidade do relatório dos auditores independentes sobre as demonstrações contábeis são questionados na prática, quando a divulgação e publicação das demonstrações não são adequadas e justas. A auditoria deve fornecer confiança a todos os usuários das informações divulgadas pela empresa (Dantas et al., 2011).

Em seguida, fez-se a análise do ano de 2014 que abrangeu 355 empresas que publicaram suas demonstrações e 107 que republicaram as demonstrações contábeis, totalizando uma amostra de 462 empresas que apresentaram todas as informações necessárias para análise. Percebe-se, analisando a média de cada grupo, que o audit delay das empresas com publicação foi de 68 dias, ao passo que a média de audit delay das empresas com republicação foi de 67 dias. O teste de Mann-Whitney, apresentado na Tabela 11, não apresentou significância (Sig. 0,834). Indica que a média dos dois grupos não difere de forma expressiva.

Tabela 11

Teste de Mann-Whitney sobre as médias de 2014

\begin{tabular}{lcccc}
\hline Grupo & N & Postos de média & Soma de classificações & Média de Audit Delay \\
\hline Publicação & 355 & 230,78 & 81928,5 & 68 \\
Republicação & 107 & 233,87 & 25024,5 & 67 \\
\hline Total & $\mathbf{4 6 2}$ & & \\
\hline U de Mann-Whitney & & 18738,5 & \\
Wilcoxon W & & 81928,5 & \\
Z & & $-0,210$ & \\
Significância Sig. (2 extremidades) & & 0,834 & \\
\hline
\end{tabular}

Fonte: Dados da pesquisa.

As médias de audit delay das empresas que republicaram ou não republicaram suas demonstrações mostrou apenas um dia de diferença. A média das publicações foi maior, com 68 dias. Esse fato contradiz o indício de que um maior audit delay pode ter vínculo com a republicação das demonstrações contábeis.

Em contraponto, a análise do ano de 2015 corroborou os resultados encontrados em 2011 e 2012, indicando uma média de audit delay significativamente diferente entre as empresas que publicaram as demonstrações contábeis apenas uma vez e as empresas que republicaram suas demonstrações. O resultado para o teste de diferença de média encontra-se a seguir na Tabela 12. 
Tabela 12

Teste de Mann-Whitney sobre as médias de 2015

\begin{tabular}{lcccc}
\hline Grupo & N & Postos de média & Soma de classificações & Média de Audit Delay \\
\hline Publicação & 312 & 187,89 & 58622,50 & 69 \\
Republicação & 92 & 252,04 & 23187,50 & 160 \\
\hline Total & $\mathbf{4 0 4}$ & & \\
\hline U de Mann-Whitney & & 9794,5 & \\
Wilcoxon W & & 58622,5 & \\
Z & & $-4,633$ & \\
Significância Sig. (2 extremidades) & & 0,000 & \\
\hline
\end{tabular}

Fonte: Dados da pesquisa.

De fato, em 2015, a média dos dois grupos analisados foi perceptivelmente diferente. $\mathrm{O}$ grupo de empresas que apresentaram republicação de demonstrações contábeis levou em média 109 dias a mais para obter o relatório do auditor em comparação ao grupo de empresas que não tiveram republicação em 2015. Por fim, analisou-se o ano de 2016, conforme apresentado na Tabela 13.

Tabela 13

Teste de Mann-Whitney sobre as médias de 2016

\begin{tabular}{lcccc}
\hline Grupo & $\mathbf{N}$ & Postos de média & Soma de classificações & Média de Audit Delay \\
\hline Publicação & 319 & 203,35 & 64867,50 & 77 \\
Republicação & 97 & 225,45 & 21868,50 & 93 \\
\hline Total & $\mathbf{4 1 6}$ & & \\
\hline U de Mann-Whitney & & 13827,5 & \\
Wilcoxon W & & 64867,5 & \\
Z & & $-1,586$ & \\
Significância Sig. (2 extremidades) & & 0,113 & \\
\hline
\end{tabular}

Fonte: Dados da pesquisa.

Em 2016, não houve diferença significativa na média de audit delay entre os dois grupos analisados. Porém, salienta-se que as empresas que não tiveram republicação das demonstrações no período apresentaram em média 16 dias a menos no prazo de divulgação do relatório de auditoria.

De modo geral, os testes de diferença de médias revelam que em 2011, 2012 e 2015 houve diferença significativa. O grupo de empresas que tiveram republicação apresentou audit delay superior ao grupo de empresas que não republicaram as demonstrações contábeis. Para os anos de 2013 e 2016, apesar de não ser constatada diferença significativa entre a média dos dois grupos, também se observou que a média de audit delay foi superior no grupo de empresas que tiveram republicação. Esses resultados fornecem indícios de que um maior audit delay está relacionado com a republicação das demonstrações contábeis.

Analisando-se, entretanto, o ano de 2014, observa-se uma inversão, visto que a média de audit delay foi ligeiramente superior para as empresas que não republicaram suas demonstrações contábeis. Deve-se observar, contudo, que a diferença de média entre os dois grupos foi de apenas 1 dia, e não se mostrou significativa.

A fim de constatar se de fato há relação entre a republicação das demonstrações contábeis e o audit delay e de aumentar, assim, a robustez dos achados, procedeu-se à análise de correlação no SPSS. A análise foi realizada por ano e os resultados encontram-se sintetizados na Tabela 14 a seguir. 
Tabela 14

Análise de correlação

\begin{tabular}{|c|c|c|c|}
\hline Ano & Variáveis & Republicação & Audit Delay \\
\hline 2011 & \begin{tabular}{|l} 
Republicação \\
Audit Delay
\end{tabular} & $\begin{array}{c}1 \\
0,211^{* *}\end{array}$ & $\begin{array}{c}0,211^{* *} \\
1\end{array}$ \\
\hline 2012 & $\begin{array}{l}\text { Republicação } \\
\text { Audit Delay } \\
\end{array}$ & $\begin{array}{c}1 \\
0,204^{* *}\end{array}$ & $\begin{array}{c}0,204^{\star \star} \\
1 \\
\end{array}$ \\
\hline 2013 & $\begin{array}{l}\text { Republicação } \\
\text { Audit Delay }\end{array}$ & $\begin{array}{c}1 \\
0,039\end{array}$ & $\begin{array}{c}0,039 \\
1\end{array}$ \\
\hline 2014 & $\begin{array}{l}\text { Republicação } \\
\text { Audit Delay }\end{array}$ & $\begin{array}{c}1 \\
-0,025\end{array}$ & $\begin{array}{c}-0,025 \\
1\end{array}$ \\
\hline 2015 & $\begin{array}{l}\text { Republicação } \\
\text { Audit Delay } \\
\end{array}$ & $\begin{array}{c}1 \\
0,399^{* *}\end{array}$ & $\begin{array}{c}0,399^{\star *} \\
1 \\
\end{array}$ \\
\hline 2016 & $\begin{array}{l}\text { Republicação } \\
\text { Audit Delay }\end{array}$ & $\begin{array}{c}1 \\
0,132^{\star *}\end{array}$ & $\begin{array}{c}0,132^{\star *} \\
1\end{array}$ \\
\hline
\end{tabular}

Nota. * A correlação é significativa em nível de $99 \%$.

Fonte: dados da pesquisa.

Observando-se a Tabela 14, pode-se constatar que os coeficientes de correlação encontrados revelam um relacionamento fraco entre as duas variáveis estudadas, visto que todos apresentaram-se menores que 0,40 (Dancey \& Reidy, 2006). Esse fato indica que pode haver outras variáveis que influenciam as correlacionadas neste estudo e que afetam assim 0 resultado (Field, 2009).

Entretanto, é interessante observar que nos anos de 2011, 2012, 2015 e 2016 o coeficiente de correlação apresentou-se maior do que nos anos de 2013 e 2014. Além disso, foram também os únicos coeficientes significativos a um nível de $99 \%$. Esse resultado converge ao teste de diferença de médias, realizado anteriormente. Confirma, assim, que quando o audit delay é maior há republicação das demonstrações contábeis, visto que o coeficiente de correlação, nos quatro anos, foi positivo.

Para o ano de 2013, o coeficiente de correlação encontrado foi muito baixo $(0,039)$ e não apresentou significância estatística, revelando uma relação fraca entre as variáveis. Entretanto, pode-se observar que o coeficiente foi positivo, indicando assim que quando o audit delay é maior há republicação das demonstrações contábeis. Esse resultado está consonante com as médias de audit delay de 2013 (68 dias para publicação e 72 dias para republicação). Porém, como as médias não diferiram significativamente, esse fato pode ter concorrido para 0 baixo coeficiente de correlação aqui encontrado.

Por fim, para o ano de 2014, constatou-se um coeficiente de correlação baixo $(-0,025)$, não significativo e negativo. Assim, diferente do que foi encontrado nos anos anteriores, em 2014, a relação entre as duas variáveis foi negativa, o que indica que quando o audit delay é maior não há republicação das demonstrações contábeis. Novamente, observa-se que o resultado aqui encontrado converge às médias anteriormente apresentadas, visto que a média de audit delay das empresas com republicação (67 dias) foi inferior à média de audit delay das empresas que não republicaram suas demonstrações (68 dias). Além disso, o baixo coeficiente encontrado pode ser reflexo da semelhança entre as médias, que não diferiram de forma significativa.

Em linhas gerais, os resultados encontrados aqui indicam que um maior audit delay está associado à republicação das demonstrações contábeis, visto que, na maioria dos anos analisados, os dados indicaram esse comportamento. Esse resultado corrobora os achados de Blankley, Hurtt e MacGregor (2014), que também evidenciaram que empresas que eventualmente republicam suas demonstrações contábeis apresentam maior atraso no recebimento do relatório de auditoria.

Essas evidências podem sugerir que o auditor teve de lidar com assuntos mais complexos no transcorrer do trabalho, que exigiram maior tempo e maior julgamento profissional. Essas situações tendem a aumentar o tempo de auditoria, o que pode consequentemente elevar a pressão sobre o auditor para que ele finalize o exame pericial. Tais fatores podem comprometer a qualidade do trabalho de auditoria, tornando-a menos eficaz na detecção de erros e desvios (Blankley et al., 2014; Ettredge et al., 2014). Assim, uma 
consequência possível da redução na qualidade da auditoria é a republicação das demonstrações que acabam sendo divulgadas ao mercado com erros ou omissões.

Supõe-se que essa seja a situação encontrada no mercado brasileiro. Desse modo, o atraso na emissão do relatório do auditor independente sinaliza um aumento no risco de auditoria, que pode futuramente resultar na ocorrência de republicação das demonstrações.

Há que se fazer uma ponderação acerca do resultado divergente encontrado em 2014. No referido ano, os resultados indicaram uma relação negativa entre o audit delay e a republicação das demonstrações contábeis. Revelaram que quanto maior 0 atraso na publicação do relatório do auditor, menor a probabilidade de republicações. De fato, uma vertente teórica entende que o atraso na publicação do relatório do auditor reflete o esforço empregado na condução da auditoria (Knechel \& Payne 2001). Evidências empíricas suportam o fato de que quanto maior o esforço empregado pela auditoria maior a qualidade do trabalho do auditor (O'Sullivan, 2000; Knechel \& Sharma, 2012). Logo, um delay maior seria desejável, uma vez que sinalizaria maior esforço por parte dos auditores e consequentemente maior qualidade da auditoria.

Acredita-se, entretanto, que essa não seja a explicação mais plausível para os resultados, visto que no mercado brasileiro os investidores reagem negativamente ao atraso na divulgação das informações contábeis (Terra \& Lima, 2006). Logo, as empresas possuem incentivos para publicarem as demonstrações de forma tempestiva. Além disso, destaca-se o fato de que as médias de audit delay encontradas para os dois grupos (publicação e republicação) foram muito próximas, o que não permite inferir a respeito da relação positiva observada entre as duas variáveis investigadas. Nesse caso, futuros estudos podem aprofundar a questão, especificamente no ano de 2014, e analisar outras variáveis aqui omitidas, como, por exemplo, o tempo de relacionamento entre auditor e auditado ou a especialização da firma de auditoria.

\section{CONCLUSÃO}

O presente estudo teve como objetivo verificar a relação entre a republicação das demonstrações contábeis das empresas brasileiras listadas na BM\&FBovespa com o audit delay. Desse modo, para atingir o objetivo geral previamente determinado procedeu-se a uma pesquisa descritiva, com abordagem quantitativa, por meio de análise documental.

O primeiro passo foi identificar as empresas listadas na BM\&FBovespa, que apresentaram republicação de suas demonstrações contábeis no período de 2011 a 2016. Esse passo foi realizado por meio do sítio eletrônico da Bolsa de Valores, Mercadorias e Futuros (BM\&FBovespa). Verificou-se que no período de 2012 houve maior incidência de republicações, com um total de 162 empresas das 463 classificadas para a análise no ano. Analisando-se por setor, percebeu-se que o mais representativo foi o "Financeiro e outros", com a maior porcentagem de participação nas republicações em todos os anos.

O segundo passo consistiu em identificar o audit delay das empresas brasileiras listadas na BM\&FBovespa. Para tanto, foram coletados dados no sítio eletrônico da BM\&FBovespa, que permitiram o cálculo do atraso na emissão do relatório do auditor independente. Neste trabalho, com fundamento na definição de Pereira (2011), utilizou-se o conceito de que um audit delay "bom" é um audit delay pequeno, ou seja, quanto menor o atraso na entrega do parecer, melhor. Os resultados mostraram que nas empresas que por algum motivo tiveram suas demonstrações republicadas, o menor audit delay é de 20 dias em 2016 e o maior prazo de 816 dias, está em 2011.

Por fim, buscou-se relacionar a republicação das demonstrações contábeis com o atraso na emissão do relatório do auditor independente sobre as demonstrações contábeis (audit delay) das empresas brasileiras listadas na BM\&FBovespa. Levando em consideração os resultados do teste de diferença de médias e da análise de correlação, constatou-se que para os anos de 2011, 2012, 2015 e 2016 um audit delay mais elevado está relacionado com a republicação das demonstrações contábeis, o que converge aos achados de Blankley et al. (2014). Assim, levando em consideração que o mercado brasileiro reage de forma negativa ao atraso na publicação das informações contábeis, entende-se que a pressão sobre o auditor 
pela rápida conclusão da auditoria pode levá-lo a reduzir a qualidade do trabalho executado, o que explica a publicação de demonstrações enviesadas.

Entretanto, para os anos de 2013 e 2014, tal relação não pôde ser verificada. Em 2013, não houve diferença significativa no audit delay dos dois grupos de empresas (que publicaram e que republicaram), o que levou a um coeficiente de correlação extremamente baixo e não significativo. Já, em 2014, as médias observadas mostraram uma relação inversa àquela esperada, ou seja, um menor audit delay relacionado com a republicação das demonstrações contábeis, fato esse confirmado pelo coeficiente de correlação identificado. Salienta-se, porém, que a relação observada não foi significativa estatisticamente, assim como a inexistência de diferença significativa entre as médias dos dois grupos analisados.

Desse modo, os resultados aqui obtidos levam à conclusão de que para os anos de 2011, 2012, 2015 e 2016, empresas com maior audit delay incorrem na republicação das demonstrações contábeis. Para os anos de 2013 e 2014, em função dos resultados relatados, não se pôde chegar à mesma conclusão.

Como todas as pesquisas, esta também possui limitações, dentre as quais destaca-se a não distinção entre refazimento e redivulgação. Como possibilidades de realização de outros estudos relacionados ao tema, sugere-se verificar se os motivos das reapresentações têm relação entre si, bem como investigar os motivos de diferença de audit delay identificados entre empresas que atuam no mesmo setor.

\section{REFERÊNCIAS}

Angeli, P. P. T. (2008). Republicação das Demonstrações Contábeis: uma análise dos índices ROA, ROE e endividamento total em empresas brasileiras no período de 2000 a 2005. Dissertação Mestrado em Ciências Contábeis, Programa de Pós-Graduação em Ciências Contábeis, da Fundação Instituto Capixaba de Pesquisa em Contabilidade, Economia e Finanças (FUCAPE), Vitória, Espírito Santo, Brasil.

Bills, K. L., Swanquist, Q. T., \& Whited, R. L. (2015). Growing pains: Audit quality and office growth. Contemporary Accounting Research, 33(1), 288-313.

Bischoff, J., Finley, J., \& Leblanc, D. (2008). Financial Statement Restatements: Causes and Effects. Tennessee CPA Journal. April.

Blankley, A. I., Hurtt, D. N., \& MacGregor, J. E. (2014). The relationship between audit report lags and future restatements. Auditing: A Journal of Practice \& Theory, 33(2), 27-57.

Brown, S. \& Hillegeist, S. A. (2007). How disclosure quality affects the level of information asymmetry. Review of Accounting Studies, 12(2-3), 443-477.

Camargo, R. C. C. P. \& Flach, L. (2016). Audit Report Lag e Expertise da Firma de Auditoria: Uma Análise com Empresas Listadas na BM\&FBovespa. Advances in Scientific and Applied Accounting, 9(2), 181-203.

Chen, S., Goo, \& Shen, Z. (2014). A Hbrid Approach of Stepwise Regression, Logistic Regression, Support Vector Machine, and Decision Tree for Forecasting Fraudulent Financial Statements. The Scientific World Journal, 2014, 1-10.

Comissão de Valores Mobiliários. (2018). Texto integral da Instrução CVM $n^{\circ}$ 480, de 7 dezembro de 2009 com as alterações introduzidas pelas Instruções CVM no 488/10, $509 / 11,511 / 11,520 / 12$, 525/12, 547/14, 552/14, 561/15, 567/15, 568/15, 569/15, 583/16, $584 / 17,585 / 17,586 / 17,588 / 17,595 / 18$ e 596/18. Dispõe sobre o registro de emissores de valores mobiliários admitidos à negociação em mercados regulamentados de valores mobiliários. Rio de Janeiro. 
Conselho Federal de Contabilidade. (2016a). NBC TA 200 (R1): Objetivos gerais do auditor independente e a condução da auditoria em conformidade com normas de auditoria. Brasília.

Conselho Federal de Contabilidade. (2016b). NBC TA 705: Modificações na opinião do auditor independente. Brasília.

Conselho Federal de Contabilidade. (2016c). NBC TA 706: Parágrafos de ênfase e parágrafos de outros assuntos no relatório do auditor independente. Brasília.

Damascena, L. G. \& Paulo, E. (2013). Pareceres de Auditoria: um estudo das ressalvas e parágrafos de ênfases constantes nas demonstrações contábeis das companhias abertas brasileiras. Revista Universo Contábil, 9(3), 104-127.

Damascena, L. G., Firmino, J. E., \& Paulo, E. (2011). Estudo sobre os pareceres de auditoria: análise dos parágrafos de ênfase e ressalvas constantes nas demonstrações contábeis das companhias listadas na Bovespa. Contabilidade Vista \& Revista, 22(1), 125-154.

Dancey, C. \& Reidy, J. (2006). Estatística Sem Matemática para Psicologia: Usando SPSS para Windows. Porto Alegre: Artmed.

Dantas, J. A., Chaves, S. M. T., Silva, M. R., \& Carvalho, R. P. (2011). Determinações de refazimento/republicação de demonstrações financeiras pela CVM: o papel dos auditores independentes. Revista Universo Contábil, 7(2), 45-64.

Ettredge, M., Fuerherm, E. E., \& Li, C. (2014). Fee pressure and audit quality. Accounting, Organizations and Society, 39(4), 247-263.

Fávero, L. P., Belfiore, P., Silva. F. L., \& Chan, B. L. (2009). Análise de dados: modelagem multivariada para tomada de decisões (2a ed.) Rio de Janeiro: Elsevier.

Field, A. P. (2009). Descobrindo a estatística usando o SPSS (2a ed.). Porto Alegre: Artmed.

Gil, A. C. (1999). Métodos e Técnicas de Pesquisa Social (5a ed.). São Paulo: Atlas.

Hair, J. F., Jr., Babin, B. J., Money, A. H., \& Samouel, P. (2005). Fundamentos de métodos de pesquisa em administração. Porto Alegre: Bookman.

He, L. \& Chiang, H. (2013). Market Reaction to Financial Statemen Restatement: A Study on the Information and Insurance Role of Auditors. Advances in Management and Applied Economics, 3(4), 37-50.

Knechel, W. R., \& J. L. Payne. (2001). Additional evidence on audit report lag. Auditing: A Journal of Practice \& Theory 20(1): 137-146.

Knechel, W. R. \& Sharma, D. S. (2012). Auditor-provided nonaudit services and audit effectiveness and efficiency: Evidence from pre-and post-SOX audit report lags. Auditing: A Journal of Practice \& Theory, 31(4), 85-114.

Lei $n^{\circ}$ 6.404, de 15 de dezembro de 1976 (1976). Dispõe sobre as Sociedades por Ações. Brasília, 15 de dezembro de 1976.

Magalhães, M. N. \& Lima, A. C. P. (2005). Noções de Probabilidade e Estatística. São Paulo: EDUSP. 
Marques, V. A., Amaral, H. F., Souza, A. A., Santos, K. L., \& Rodrigues, P. H. (2017). Determinantes das Republicações no Mercado Brasileiro: Uma Análise a partir dos Incentivos ao Gerenciamento de Resultados. Revista de Educação e Pesquisa em Contabilidade, 11(2), 191-213.

Martins, G. A \& Theóphilo, C. R. (2009). Metodologia da investigação científica para ciências sociais aplicadas (2a ed.). São Paulo: Atlas.

Murcia, F. D. R. \& Borba, J. A. (2005). Um estudo das fraudes contábeis sob duas óticas: Jornais econômicos versus periódicos acadêmicos no período de 2001-2004. Revista de Contabilidade do Mestrado de Ciências Contábeis da UERJ, 10(2), 99-114.

Murcia, F. D.R. \& Carvalho, L. N. (2007). Conjecturas Acerca do Gerenciamento de Lucros, Republicação das Demonstrações Contábeis e Fraude Contábil. Contabilidade Vista \& Revista, 18(4), 61-82.

Niyama, J. K. \& Silva, C. A. T. (2011). Teoria da Contabilidade. (2a ed.). São Paulo: Atlas.

Netto, F. H. \& Pereira, C. C. (2011). Impacto da republicação de demonstrações financeiras no preço das ações de empresas brasileiras. Revista Contemporânea de Contabilidade, 7(14), 29-50.

O'Sullivan. (2000). The impact of board composition and ownership on audit quality: Evidence from large UK companies. The British Accounting Review, 32(4), 397-414.

Pereira, A. N. \& Costa, F. M. (2012). Determinantes do atraso de auditoria externa (Audit Delay) em companhias brasileiras. Encontro da Associação Nacional de Programas de Pós-Graduação em Administração (ENANPAD), Rio de Janeiro (RJ).

Pereira, A. N. (2011). Determinantes do atraso de auditoria externa (Audit Delay) em companhias brasileiras. Dissertação de Mestrado em Ciências Contábeis, Programa de Pós-Graduação em Ciências Contábeis, da Fundação Instituto Capixaba de Pesquisa em Contabilidade, Economia e Finanças (FUCAPE), Vitória, Espírito Santo, Brasil.

Raupp, F. M. \& Beuren, I. M. (2003). Metodologia da Pesquisa Aplicável às Ciências Sociais. In Ilse M. Beuren (Org). Como elaborar trabalhos monográficos em contabilidade: teoria e prática (Cap. 3, pp. 76-97). São Paulo: Atlas.

Romanus, R. N., Maher, J. J., \& Fleming, D. M. (2008). Auditor industry specialization, auditor changes, and accounting restatements. Accounting Horizons, 22(4), 389-413.

Santos, A. C., Souza, M. A., Machado, D. G., \& Silva, R. P. (2009). Auditoria independente: um estudo dos pareceres emitidos sobre demonstrações contábeis de empresas brasileiras listadas na Bovespa e na Nyse. Revista Universo Contábil, 5(4).

Stevenson, W. J. (2001). Estatística aplicada a administração. Editora Harbra.

Teixeira, S. A., Politelo, L., \& Klann, R. C. (2013). Fatores relacionados ao refazimento das demonstrações contábeis das companhias brasileiras de capital aberto. Encontro Nacional dos Cursos de Graduação em Administração, Florianópolis, SC, 24.

Terra, P. R. S., \& De Lima, J. B. N. (2006). Governança corporativa e a reação do mercado de capitais à divulgação das informações contábeis. Revista Contabilidade \& Finanças, 17(42), 35-49. 